\title{
Analysis of Influencing Factors on Regional Carbon Emission Intensity in China-Based on Empirical Research with Provincial Panel Data
}

\author{
Shih-Feng Tsai ${ }^{1}$ \\ ${ }^{1}$ Institute of Taiwan Studies ,School of Public Policy and Management, Tsinghua University, Beijing, China \\ Correspondence: Shih-Feng Tsai, School of Public Policy and Management, Tsinghua University, Beijing \\ 100084, China. Tel: 86-182-0101-8368. E-mail: a8565257@gmail.com
}

Received: March 28, 2014 Accepted: May 6, 2014 Online Published: May 12, 2014

doi:10.5539/jsd.v7n3p83 URL: http://dx.doi.org/10.5539/jsd.v7n3p83

\begin{abstract}
This thesis analyzes the influencing factors of carbon emission intensity based on the five types of panel data in 31 provinces (cities and autonomous regions) throughout China collected in China's "12th Five-Year Plan", and has conclusions as follows: the carbon intensity in various regions is mainly influenced by energy intensity, economic growth, proportion of the secondary industry, and fiscal expenditure. The carbon intensity basically maintains positive correlation with energy intensity and economic growth, while the correlation between carbon intensity and industrial structure, and that between carbon intensity and fiscal expenditure varies from each other. There are different industrial structures and corresponding changing laws in various provinces and cities. The favorable influences on carbon intensity by fiscal expenditure are not remarkable, and yet the relationship between proportion of fiscal expenditure and carbon intensity still shows positive correlation in most of the provinces. In the long run, the major way of realizing energy saving and emission reduction for various provinces still lies in adjustment and optimization of both industrial structure and energy consumption structure.
\end{abstract}

Keywords: carbon intensity, energy saving and emission reduction, change of industrial structure

\section{Introduction}

Numerous scholars and policy makers at home and abroad have carried out in-depth exploration into energy saving, carbon reduction and low-carbon development for adapting to climatic changes. Most of them mainly investigate from three different perspectives according to different conditions in various countries: Firstly, the driving factors of carbon emission, and the relation between carbon emission and economic growth; Secondly, approaches and mechanism for realizing low-carbon economy, for example, exploration into carbon trade and carbon taxation system; Thirdly, cooperation and coordination mechanism for low carbon and emission reduction among various countries under the global background. Generally, even in developing countries during economic development it is encouraged to improve the destructive activities on environment through more effective use of investment and subsidy. There are ways such as adjusting influences caused by pollution through market measures. Many research models explore the mutual influences among energy, economy and environment. Table 1 explains the major categories of these models. In macro aspect the changes in macroeconomic indexes caused by changes in emission reduction policy fall within the Top-Down model, which is represented by CGE model and MACRO model that are applicable to macro-economy simulation based on market mechanism. The limitation of the Top-Down model is that the description of production and technical utilization is relatively abstract, and the causes of changes in energy price and consumption are unclear. Thus in empirical literature EKC (Environmental Kuznets Curve) is often used to make different analysis. The evidences put forth by Unruh and Moomaw (1998) show that EKC does not represent the development of pollution emission traces in different countries. Rather it indicates the pollution traces invarious countries during the same historical events and in a broad sense their sudden income changes. In another study Suri and Chapman (1998) examine the relation between EKC hypothesis and commercial energy consumption with trans-regional and time sequence, and suggest that the growth in energy demands of industrialization and exported finished products of industrialized countries have far outgrown energy consumption. Selden, Forrest and Lockhart (1999) observe the emission tendencies of 6 air pollutants in past years from 1970 to 1990 in America and show that there is a relation in the shape of a reverse $U$ between pollutants emission of various forms and GDP. They interpret this shape to be the primary reason for decrease in the pollution emission and discover five effects: scale effect, 
composition effect, energy intensity effect, energy mix effect, and technique effect. Fan Jin (2000) points out that it is almost impossible to reach the turning point in the reverse U-shaped relation. If the urban energy consumption structure cannot be improved, pollution will deteriorate continuously due to economic development. The research results of Bruvoll and Medin (2003) show that lowering energy concentration degree is the most important way to reduce carbon dioxide emission. The importance of improving energy structure is only second to the importance of lowering energy concentration degree in emission reduction. Lee and Oh (2006) through the research on APEC countries find that per capita GDP and population are the main factors affecting carbon emissions. Claudia et al. (2010) study Mexico's steel industry in 1970-2000 and state that the energy mix and technology effect cannot offset the scale effect caused by the growth of carbon emissions.

Table 1.The category of regular carbon emission reduction analysis model

\begin{tabular}{|c|c|c|c|}
\hline Category & $\begin{array}{l}\text { Representative } \\
\text { model }\end{array}$ & Regular model & Representative literatures \\
\hline \multirow[b]{2}{*}{ Top-Down } & \multirow[b]{2}{*}{ CGE } & & Arvydas (2000); Toshihiko (2004) \\
\hline & & MACRO;GEM & $\begin{array}{l}\text { Lim (1998); Proost (1992); Robinson } \\
\text { (1999) }\end{array}$ \\
\hline \multirow{2}{*}{ Down-top } & \multirow{2}{*}{ MARKAL } & EFOM & Dolf(2001); Hannele(2004); Mikiko \\
\hline & & AIM;I/O & \\
\hline
\end{tabular}

Source: reproduced from literature.

Angle (1997), based on the endogenous economic growth theory, discusses the research and development investment intensity, technology transfer, and foreign technology absorption capacity factors such as the impact on China's carbon emissions, the more energy consumption, the higher the income level. The researcher concludes that the greater openness will tend to lead to the more $\mathrm{CO}_{2}$ emissions.

In China, Chinese economic scholars in carbon emission research have mostly explored the individual factors influencing carbon emission from the national perspective. For example, Wu et al. (2005) analyze China's 1996-1999 carbon emissions and suggest that the decline is mainly due to China's energy intensity and the average labor productivity growth. Xu et al. (2006) state that China's per capita carbon emissions is the main reason for the increase or decrease level of economic development (scale), and the intensity of energy and structural change is not significant influence on per capita carbon emissions. Chen (2001) and Fang (2007) examine Chinese forest carbon inventory and changes in average carbon density using improved biomass conversion factor method. Huang (2008) investigates the government subsidy quota in policy support for industrial development. Yu (2010) inquires into the concept that the government may realize sustainable development objectives of carbon-sink forestry under the guidance of commission-agency mechanism etc.. This study, however, points out that there are different developmental phases and environmental backgrounds in different regions, thus there are different factors influencing carbon intensity in various regions.

The present research, in the scope of the existing research and discussion, explores the common factors and different ones in different regions through studying the influences of macroeconomic development, government policy and industrial structure on the carbon dioxide emission per unit of GDP from the perspectives of different provinces in China. The complexity of this study thus leads to a rather complex data composition and certain inevitable limitation of such data, especially with the concern of the duration of years. Unlike other researchers' ways of classification, such as YUE (2010) who divides provinces into East, Central and West three categories, we classify various domestic provinces according to the data recorded in the "12th Five-Year Planning" of China, and carry out the analysis of the influences of each factor on carbon intensity with panel data model.

\section{Research Methods and Data Analysis}

Based on the data collected through the provincial disintegration program for energy saving and emission reduction in China's " $12^{\text {th }}$ Five-Year Plan", we study the carbon emission and influencing factors of various domestic provinces and cities. Classifying the data of various provinces in China, we collect 7 variables: namely, energy intensity, industrial structure, economic development speed, proportion of local fiscal expenditure, proportion of state-owned energy industry, proportion of environmental pollution control, and proportion of total area of forestation, and interpret the data according to these variables. 


\subsection{Provincial Carbon Emission in China}

The carbon emission situation and influencing factors in various provinces are explored from the point of view of provincial low-carbon economic development in inland areas of China. As shown in the total data on provincial carbon emission in 2009, the provinces and cities with more carbon emission are Shandong, Hebei, Guangdong, Jiangsu, Liaoning and Inner Mongolia in turn. The carbon emission of these 5 provinces all exceed 400 million tons. Listed behind them are 9 provinces such as Henan, Zhejiang, Shanxi, Sichuan, Hubei, Shanghai, Heilongjiang, Hunan and Anhui, with the carbon emission being 240 million tons. The carbon emission of the other provinces is relatively low, especially, in Ningxia, Qinghai and Hainan etc., where the carbon emission is below 100 million tons. From the point of view of different economic scales in various provinces, the carbon dioxide emission of the provinces with a high total GDP value in the year is relatively high, for example, Guangdong, Jiangsu, Shandong, Zhejiang, Henan and Liaoning etc..

The carbon emission scale can be roughly divided into the following categories: super-heavy, heavy, general and light (See Table 2). The number of provinces with super-heavy carbon mission over 100 million tons in 2009 is 0 . This number reflects an improvement compared with the total number of 3 provinces with super-heavy carbon emission in 2005. The provinces with heavy carbon emission are mainly eastern provinces, for example, Shandong, Hebei, Guangdong, Jiangsu, Liaoning and Zhejiang. The provinces and cities with ordinary carbon emission are mainly central and western cities and provinces, for example, Shanxi, Hubei, Heilongjiang, Hunan, Anhui, Jilin and Jiangxi etc.. Except Hainan Province, the provinces and cities with light carbon emission are all in western regions. Therefore to briefly sum up, the carbon emission of economically developed eastern regions is higher, while that of underdeveloped central and western provinces is low. In other words, carbon emission plays a powerful promoting role in economic development. From the point of view of regional economic development, though the economic development level of eastern regions has achieved a preliminary scale with a prospect of lowering carbon emission, central regions still face the pressure from the increase of carbon emission along with the gradually quickening pace of the rise of these regions, which in a sense also brings about pressure to cause an increase of carbon emission in the whole country.

Table 2. Categories of provincial carbon emission in mainland China (2009) Unit: Million Tons

\begin{tabular}{|c|c|c|c|}
\hline \multirow{2}{*}{$\begin{array}{l}\text { Category } \\
\text { Sup-Heavy }\end{array}$} & \multirow[b]{2}{*}{$(>=10000)$} & \multirow{2}{*}{$\begin{array}{l}\text { Province } \\
-\end{array}$} & \multirow[t]{2}{*}{ Region } \\
\hline & & & \\
\hline & $\mathrm{I}(9999 \sim 6000)$ & Shandong(67611) & East 1 \\
\hline Heavy & $\mathrm{II}(5999 \sim 3000)$ & $\begin{array}{l}\text { Hebei(51743); Guangdong(48433); Jiangsu(48401); } \\
\text { Liaoning(42437); Nei Mongol(41582) Henan(38938); } \\
\text { Zhejiang(31236) }\end{array}$ & $\begin{array}{l}\text { East } 5 \\
\text { Central } 2\end{array}$ \\
\hline \multirow[t]{2}{*}{ General } & $\mathrm{I}(2999 \sim 2000)$ & $\begin{array}{l}\text { Shanxi(28117); Sichuan (26839);Hubei(26806)、 } \\
\text { Shanghai(23241);Heilongjiang(22689);Hunan(22091);Anh } \\
\text { ui(20950) }\end{array}$ & $\begin{array}{l}\text { East } 1 \\
\text { Central } 5 \\
\text { West } 1\end{array}$ \\
\hline & $\mathrm{II}(1999 \sim 1000)$ & $\begin{array}{l}\text { Shaanxi(17834); Jilin(17744); } \\
\text { Fujian(17388);Guizhou(17274); Yunnan(16861); } \\
\text { Xinjiang(15828);Guangxi(13061); Tianjin(12963); } \\
\text { Chongqing(12411); Beijing(12347); } \\
\text { Jiangxi(11900);Gansu(10279) }\end{array}$ & $\begin{array}{l}\text { East } 3 \\
\text { Central } 2 \\
\text { West } 6\end{array}$ \\
\hline Light & $(<=999)$ & Ningxia(6895); Qinghai(3360); Hainan(3083); Tibet(NA) & $\begin{array}{l}\text { East } 1 \\
\text { Central } 3\end{array}$ \\
\hline
\end{tabular}

Note. There is no relevant statistical data in Tibetan areas. 


\subsection{Research Methods}

Most of the existing analyses of the factors contributing to carbon emission reduction concentrate on the perspectives including the population revealed by Kaya formula, GDP and energy consumption and carbon transfer in international commodity trade etc.. Their analytical thoughts are basically consistent. The distinction mainly lies in: firstly, there are different targets for analysis, some of which are analyses of total carbon emission, some are analyses of carbon emission per capita, and some are analyses of carbon emission of unit GDP; secondly, based on the characteristics of economic and resource structure in the countries and regions where various scholars are located, they focus on extracting different factors for analysis; thirdly, single-factor relevant analyses of industrial structure of carbon emission, population structure or regional structure are conducted from different perspectives based on different areas studied. Based on these existing study results, various factors and economic development characteristics of the whole China and various provinces are integrated and added into this paper in order to explore the influence over carbon intensity wielded by the government input and environmental treatment. The factors added include: (1) the percentages of energy consumptions in various provinces accounting for their GDP; (2) the percentages of values added to the second industry accounting for GDPs in various provinces; (3) economic growth rates in various provinces; (4) the percentages of locally fiscal expenditure accounting for GDP; (5) the percentages of energy industry investments accounting for GDPs in various provinces; (6) the percentages of environmental pollution treatment and its investment accounting for GDP and (7) total forestation area accounting for GDP etc.. These factors are added to perform an analysis of carbon intensity per GDP in various provinces. The chosen factors are listed in Table A1.

The data adopted herein comes from China Statistical Yearbook, China Statistical Yearbook on Environment, and relevant public and unpublicized data. Due to the limited number of samples, the carbon emission data of various provinces, and energy consumption data are obtained through converting the energy balance table in "China Energy Statistical Yearbook", while the proportion of the added value in the secondary industry, the economic growth rate, and the proportion of fiscal expenditure are calculated according to the relevant data of CCER. The proportion of investment on state-owned energy industry, the proportion of investment amount on environmental pollution control, and the proportion of total area of forestation in various provinces come from "China Statistical Yearbook on Environment".

Due to the different levels of carbon emission and carbon intensity in various provinces, many factors need to be considered, for example, geographic environmental factor, natural resource factor and policy factor etc.. There tends to be lack, omission or incompletion of data due to the excessive number of provinces. Thus we have made use of the panel model to analyze the factors influencing carbon emission in each province of China. Similar to the analysis of the factors influencing carbon intensity of various countries, the driving factors of provincial carbon intensity are mainly interpreted with 7 variables listed above. It is challenging to carry out panel model analysis for 31 provinces simultaneously due to the excessive number of provinces and the different developmental stages in different regions of China. Therefore classification has been carried out for the provincial disintegration program by National Development and Reform Commission of People's Republic of China based on the energy-saving and emission reduction objective in China's "12th Five-Year Planning". An analysis of individual category has also been made using the panel data model.

Table 3. Disintegration Program for Energy-Saving Objectives in "12th Five-Year Plan"

\begin{tabular}{llc}
\hline Province, City, Autonomous Region & $\begin{array}{c}\text { Consumption Intensity Index } \\
\text { Per Unit GDP (Unit \%) }\end{array}$ \\
\hline I & Tianjin; Shanghai; Jiangsu; Zhejiang; Guangdong & 18 \\
II & Beijing; Hebei; Liaoning; Shandong & 17 \\
III & Shanxi; Jilin; Heilongjiang; Anhui; Fujian; Jiangxi; Henan; & 16 \\
IV & Hubei; Hunan; Chongqing; Sichuan; Shaanxi & 15 \\
V & Hainan; Tibet; Qinghai; Xinjiang & 10 \\
\hline
\end{tabular}

Source: China Low-Carbon Development Report (2012). 
In order to form suggestions about relevant policy proposals that will realize the state energy-saving and emission reduction, this paper establishes panel data models under 5 categories of the provinces (cities, autonomous regions) respectively, and explores the driving force and obstructive factors for low-carbon economy in each block. The formal configuration of the model is as follows:

$$
I_{t}+\beta_{2} D_{t}+\beta_{3} g_{-} G_{\text {GPP }}+\beta_{4} \text { DG }_{t}+\beta_{5} E_{-} \text {nat }_{t}+\beta_{6} \text { EPI }_{t}+\beta_{7} \text { Fore }_{t}+\varepsilon_{t}
$$

The data is collected during 2003 and 2009, covering 30 provinces (cities, autonomous regions) except Tibet. The data on carbon intensity and energy intensity are obtained through converting the energy balance table in "China Energy Statistical Yearbook", and the proportion of the added value of the secondary industry, the economic growth rate, and the proportion of fiscal expenditure are calculated according to relevant CCER data. The proportion of investment on state-owned energy industry, the proportion of investment on environment pollution control, and the proportion of total forestation area in various provinces etc. are from "China Statistical Yearbook on Environment". See Table 4 for the specific meanings of the variables:

Table 4. Selection and meaning of variables in the model

\begin{tabular}{|c|c|c|c|}
\hline Variable & Meaning & Index Calculation & Unit \\
\hline LCI & Carbon Intensity & $\begin{array}{l}\mathrm{Ln}(\text { carbon emission of various } \\
\text { provinces/GDP of various provinces) }\end{array}$ & $\begin{array}{l}\text { Tons of } \mathrm{CO}_{2} / \\
10,000 \text { Yuan }\end{array}$ \\
\hline LEI & Energy Intensity & $\begin{array}{l}\text { Ln(Energy Consumption of Each Province/ } \\
\text { GDP of various provinces) }\end{array}$ & $\begin{array}{l}\text { Tons of Standard } \\
\text { Coal } / 10,000 \text { Yuan }\end{array}$ \\
\hline DI & Industrial Structure & $\begin{array}{l}\text { Added Value of Second Industry of Each } \\
\text { Province/ GDP of various provinces) }\end{array}$ & $\%$ \\
\hline g_GDP & Economic Growth & Growth rate of regional GDP & $\%$ \\
\hline DG & Fiscal expenditure & $\begin{array}{l}\text { Total amount of local fiscal } \\
\text { expenditure/regional GDP }\end{array}$ & $\%$ \\
\hline EI_nat & $\begin{array}{l}\text { State-owned energy } \\
\text { industrial investment }\end{array}$ & $\begin{array}{l}\text { Investment on state-owned energy industry in } \\
\text { each province/regional GDP }\end{array}$ & $\%$ \\
\hline EPI & $\begin{array}{l}\text { Investment on } \\
\text { environmental pollution } \\
\text { control }\end{array}$ & $\begin{array}{l}\text { Investment on environmental pollution } \\
\text { control of each province/regional GDP }\end{array}$ & $\%$ \\
\hline Fore & Total forestation area & $\begin{array}{l}\text { Total forestation area of each } \\
\text { province/national total area of forestation }\end{array}$ & $\%$ \\
\hline
\end{tabular}

Eviews software is used in this study to carry out analysis with panel data. Due to the small quantity of data and a large number of variables, "slope coefficients of different interpretative variables in different sectional individuals" are not distinguished here, and all the interpretative variables are ordinary ones in the model configuration to guarantee degree of freedom. The value under cross-section specific is empty, while the intercept item is adopted as the mixed variable model uniformly estimates.

\section{Analysis of Influencing Factors of Provincial Carbon Emission-Analysis Based on Panel Data Model}

\subsection{Research on Influencing Factors of the Carbon Intensity of the First Category of Provinces (Cities)}

The first category of provinces and cities for emission reduction in the disintegration program for energy saving and emission reduction in "12th Five-Year Plan" includes 5 provinces and cities that are Tianjin, Shanghai, Jiangsu, Zhejiang and Guangdong; all belong to coastal developed regions. The results of model regression are in Table 5: 
Table 5. Results of panel data model regression of the first category of provinces (1)

\begin{tabular}{lllll}
\hline Variable & Coefficient & Std. Error & t.-Statistic & Prob. \\
\hline C & 0.800723 & 0.586680 & 1.364837 & 0.1836 \\
LEI? & 2.703903 & 0.435200 & 6.213011 & 0.0000 \\
DI? & -3.408671 & 1.446981 & -2.355712 & 0.0260 \\
G_GDP? & 1.397369 & 0.923118 & 1.513749 & 0.1417 \\
DG? & 1.699141 & 0.885183 & 1.919536 & 0.0655 \\
EPI? & 28.89310 & 9.525182 & 3.033338 & 0.0053 \\
EI_NAT? & -2.430311 & 5.923701 & -0.410269 & 0.6848 \\
FORE? & -4.419829 & 9.285560 & -0.475990 & 0.6379 \\
R-squared & 0.822013 & Mean dependent var. & 1.960794 \\
Adjusted R-squared & 0.775868 & S.D. dependent var. & 0.446564
\end{tabular}

Note. ${ }^{*}$ indicates significance at 0.1 level; **indicates significance at 0.05 level; ***indicates significance at 0.01 level

Based on these results, there are mainly the following problems: firstly, there is rather insignificant statistical quantity of the variables EI_nat and Fore; secondly, the coefficient symbol of the variable EI_nat is in question. Logically, the increase of investment on state-owned energy industry will necessarily lead to a rise in energy production and consumption and thus an increase in carbon emission. Therefore, the two shall have positive correlation theoretically. As the two variables are not significant, the regression of the model is carried out again after deleting the aforesaid two variables. The results are shown in Table 6 . The significance of the parameters has been significantly improved. The estimation formula of regression is as follows:

$$
\begin{aligned}
\mathrm{LCI}_{\mathrm{t}}=\mathrm{C}+\beta_{1} \mathrm{LELCI}_{\mathrm{t}}= & 0.9040+2.7716 \mathrm{LEI}_{\mathrm{t}}-3.8442 \mathrm{DI}_{\mathrm{t}}+1.4292 \mathrm{~g}_{-} \mathrm{GDP}_{\mathrm{t}}+1.4843 \mathrm{DG}_{\mathrm{t}}+29.3965 \mathrm{EPI}_{\mathrm{t}} \\
& (1.70) \quad(7.23)
\end{aligned}
$$

It can be seen that as for the first category of provinces, the major factors influencing carbon intensity are energy intensity, industrial structure, economic growth rate, fiscal expenditure and investment on environmental pollution control. Specifically, carbon intensity is positively correlated to energy intensity and economic growth, and complies with the basic logic. The proportion of the added value of the second industry is negatively correlated to carbon intensity mainly because the economic development of such provinces is rapid, and the optimization and adjustment of industrial structure also rank in the forefront. What is worth of attention is that the increase of fiscal expenditure will not necessarily lead to decrease of carbon intensity, which may be due to the fact that the major orientation of local government fiscal expenditure is economic construction instead of energy saving and emission reduction. Moreover, the increase of the investment on environment pollution control has not decreased carbon intensity, either, because such investment is mainly used for post-control, and mainly for control of industrial waste gases (carbon dioxide), waste water and solid particle pollution etc..

Table 6. Results of panel data model regression of the First Category of Province (2)

\begin{tabular}{lllll}
\hline Variable & Coefficient & Std. Error & t-Statistic & Prob. \\
\hline C & 0.904023 & 0.530528 & 1.704006 & 0.0991 \\
LEI? & 2.771622 & 0.383380 & 7.229443 & 0.0000 \\
DI? & -3.844267 & 1.120111 & -3.432040 & 0.0018 \\
G_GDP? & 1.429195 & 0.891785 & 1.602622 & 0.1199 \\
DG? & 1.484264 & 0.750591 & 1.977459 & 0.0576 \\
EPI? & 29.39645 & 8.983241 & 3.272366 & 0.0028 \\
R-squared & 0.820280 & Mean dependent var. & 1.960794 \\
\hline Adjusted R-squared & 0.789294 & S.D. dependent var. & 0.446564 \\
\hline
\end{tabular}




\subsection{Research on Influencing Factors of the Carbon Intensity of the Second Category of Provinces (Cities)}

The second category of provinces and cities in the disintegration program for energy saving and emission reduction in the "12th Five-Year Plan" includes 4 inland provinces with a large economic scale such as Beijing, Hebei, Liaoning and Shandong. According to the regression results obtained in the way similar to that in section 3.1, only the coefficients of the two variables such as LEI and EI_nat are relatively significant. Therefore, the variables shall be adjusted again. After the insignificant variables are deleted and the influence of the industrial structure of different provinces on the differences of carbon intensity are put into consideration, the regression model of the mode has been significantly improved. The results are shown in Table 7.

Table 7. The results of panel data model regression of Second Category of Province

\begin{tabular}{lllll}
\hline Variable & Coefficient & Std. Error & t-Statistic & Prob. \\
\hline C & 3.572902 & 1.806553 & 1.977745 & 0.0654 \\
LEI? & 1.376269 & 0.466935 & 2.947453 & 0.0095 \\
G_GDP? & 1.870738 & 1.094840 & 1.708686 & 0.1068 \\
DG?(-1) & -10.70026 & 4.857985 & -2.202614 & 0.0426 \\
BJ_DIBJ & -5.515110 & 3.750980 & -1.470312 & 0.1609 \\
HB_DIHB & -4.747974 & 2.782511 & -1.706363 & 0.1073 \\
LN_DILN & -1.998096 & 2.064097 & -0.968024 & 0.3474 \\
SD_DISD & -3.628317 & 2.193540 & -1.654092 & 0.1176 \\
R-squared & 0.967237 & Mean dependent var. & 2.872229 \\
Adjusted R-squared & 0.952903 & S.D. dependent var. & 1.021007 \\
\hline
\end{tabular}

The carbon intensity of these four provinces and cities is all related to energy intensity, economic growth, industrial structure and fiscal expenditure. The carbon intensity is positively related to energy intensity and economic growth, and negatively related to fiscal expenditure. This means to these provinces and cities, the increase in the proportion of the fiscal expenditure in the previous period is beneficial for emission reduction. Moreover, the fact that carbon intensity shows negative correlation of different extents to the added value of the second industry suggests a relation to the changes of industrial structure of each province.

\subsection{Research on Influencing Factors of the Carbon Intensity of the Third Category of Provinces (Cities)}

The fourth category of provinces and cities under the disintegration program of "12th Five-Year Plan" energy-saving and emission reduction plan includes totally 12 provinces (cities or autonomous regions) Shanxi, Jilin, Heilongjiang, Anhui, Fujian, Jiangxi, Henan, Hubei, Hunan, Chongqing, Sichuang and Shaanxi. The regression results show that the significance of the variables DI and EI nat is low. Model regression is carried out again after making a series of adjustments such as deleting the insignificant variables, variables with reverse symbols, and considering the different influences of the proportion of fiscal expenditure of different provinces. The results are basically satisfactory. The regression results are in Table 8: 
Table 8 . The results of panel data model regression of the Third Category of Provinces

\begin{tabular}{lllll}
\hline Variable & Coefficient & Std. Error & t-Statistic & Prob. \\
\hline C & 1.252452 & 0.654045 & 1.914934 & 0.0611 \\
LEI? & 2.648903 & 0.218318 & 12.13324 & 0.0000 \\
DI? & -6.124513 & 1.334360 & -4.589849 & 0.0000 \\
G_GDP? & 1.272645 & 0.733907 & 1.734067 & 0.0889 \\
SX_DGSX(-1) & -5.090434 & 1.694652 & -3.003823 & 0.0041 \\
JL_DGJL(-1) & 5.087789 & 1.100835 & 4.621754 & 0.0000 \\
HLJ_DGHLJ(-1) & 7.022719 & 1.238514 & 5.670277 & 0.0000 \\
AH_DGAH(-1) & 5.792909 & 1.496553 & 3.870833 & 0.0003 \\
FJ_DGFJ(-1) & 9.967960 & 2.960665 & 3.366798 & 0.0015 \\
JX_DGJX(-1) & 7.167780 & 1.793047 & 3.997542 & 0.0002 \\
HN_DGHN(-1) & 10.08153 & 2.140424 & 4.710060 & 0.0000 \\
HUN_DGHUN(-1) & 0.790376 & 1.565483 & 0.504877 & 0.6158 \\
CQ_DGCQ(-1) & 1.735505 & 1.061524 & 1.634918 & 0.1082 \\
SC_DGSC(-1) & -2.610983 & 1.452430 & -1.797665 & 0.0782 \\
SSX_DGSSX(-1) & 5.531427 & 1.246971 & 4.435890 & 0.0000 \\
R-squared & 0.932069 & Mean dependent var. & 2.783476 \\
Adjusted R-squared & 0.913421 & S.D. dependent var. & & 0.903909 \\
\hline
\end{tabular}

The carbon intensity of these 12 provinces or autonomous regions is related to energy intensity, economic growth, industrial structure and fiscal expenditure. Carbon intensity is positively related to energy intensity and economic growth, and negatively related to the added value of the second industry. However, the relation between carbon intensity and the proportion of fiscal expenditure is relatively complex. The increase of fiscal expenditure is beneficial to decrease of carbon intensity in some provinces, for example, Shanxi and Sichuan. However, for most of the provinces, the increase of fiscal expenditure does not lower carbon intensity.

\subsection{Research on Influencing Factors of the Carbon Intensity of the Fourth Category of Provinces (Cities)}

The fourth category of provinces and cities under the "12th Five-Year Plan" disintegration program plan includes 6 provinces or autonomous regions such as Inner Mongolia, Guangxi, Guizhou, Yunnan, Gansu and Ningxia. There are following problems in the results of model regression of mixed variables: firstly, the statistical quantity of the variables g_GDP, DG and t of EPI is rather significant; secondly, the coefficient symbol of the secondary EI, EI_nat and Fore is in question. Logically, the increase in the amount of investment on state-owned energy industry will necessarily lead to a rise in energy production and consumption, and thus an increase in carbon emission. The two are therefore expected to be positively correlated theoretically. Moreover, the increase of forestation area is beneficial to absorption of carbon dioxide in the atmosphere, and the two shall be negatively related. After we delete the variables EPI, EI_nat and Fore, and carry out the first-order time delay of fiscal expenditure DG, Model regression is run one more time. The significance of the model is then improved to some extent. The results are listed in the following Table 9: 
Table 9. The results of panel data model regression of the Fourth Category of Provinces

\begin{tabular}{lllll}
\hline Variable & Coefficient & Std. Error & t-Statistic & Prob. \\
\hline C & 3.353888 & 2.591666 & 1.294105 & 0.2070 \\
LEI? & 1.939683 & 0.375838 & 5.160956 & 0.0000 \\
DI? & -2.703613 & 3.756328 & -0.719749 & 0.4781 \\
G_GDP? & -1.014882 & 1.802747 & -0.562964 & 0.5783 \\
NM_DGNM(-1) & -1.833235 & 6.256280 & -0.293023 & 0.7718 \\
GX_DGGX(-1) & -12.53468 & 8.834858 & -1.418776 & 0.1678 \\
GZ_DGGZ(-1) & -53264.92 & 42893.20 & -1.241803 & 0.2254 \\
YN_DGYN(-1) & -88078.34 & 58176.47 & -1.513986 & 0.1421 \\
GS_DGGS(-1) & -7.698831 & 5.077929 & -1.516136 & 0.1415 \\
NX_DGNX(-1) & -6.108089 & 4.394768 & -1.389855 & 0.1764 \\
R-squared & 0.957108 & Mean dependent var. & 4.974706 \\
Adjusted R-squared & 0.942261 & S.D. dependent var. & & 2.137449 \\
\hline
\end{tabular}

The carbon intensity of these 6 provinces or autonomous regions is related to energy intensity, economic growth, industrial structure and fiscal expenditure. Carbon intensity is positively related to energy intensity, and negatively related to the economic growth and the added value of the second industry. However, the relation between carbon intensity and the proportion of fiscal expenditure is negatively correlated to various extents, i.e. for those under this particular category of provinces and cities the increase of the proportion of the fiscal expenditure of the previous period is beneficial to emission reduction.

\subsection{Research on Influencing Factors of the Carbon Intensity of the Fifth Category of Provinces (Cities)}

The fifth category of provinces and cities under the disintegration program of "12th Five-Year Plan" energy saving and emission reduction plan includes 4 provinces (or autonomous regions) such as Hainan, Tibet, Qinghai and Xinjiang. Due to lack of data on Tibet Autonomous Region, there are only three sectional individuals in the model. There are following problems in the results of model regression of mixed variables: firstly, the statistical quantity of the variable DG and EPI is rather insignificant; secondly, the coefficient symbol of the variable EI_nat is in question. Logically, the increase of investment on state-owned energy industry will necessarily lead to a rise in energy production and consumption, and an increase in carbon emission, and therefore the two are expected to be positively related theoretically. Model regression is applied again after the variables EPI、EI_nat and Fore are deleted and the first-order time delay of fiscal expenditure DG is carried out. The results are listed in Table 10:

Table 10. The results of panel data model regression of the Fifth Category of Province

\begin{tabular}{lllll}
\hline Variable & Coefficient & Std. Error & t-Statistic & Prob. \\
\hline C & 1.710565 & 0.735852 & 2.324605 & 0.0384 \\
LEI? & 1.878183 & 0.472917 & 3.971483 & 0.0019 \\
DI? & -11.57208 & 5.466241 & -2.117009 & 0.0558 \\
G_GDP? & 5.738634 & 2.616151 & 2.193541 & 0.0487 \\
DG?(-1) & 3.927148 & 3.890261 & 1.009482 & 0.3327 \\
FORE? & 54.57114 & 15.86238 & 3.440288 & 0.0049 \\
R-squared & 0.892819 & Mean dependent var. & 3.638256 \\
Adjusted R-squared & 0.848160 & S.D. dependent var. & 1.099282 \\
\hline
\end{tabular}


The significances of the parameters in the model is improved, but the coefficient of the variable Fore is significantly positive, which is inconsistent with the practical conditions. In addition, the expansion of forestation area will necessarily reduce the emission of carbon dioxide in the atmosphere. Such regression results may be due to a too small number of samples and excessive variables. The estimation formula of regression obtained after further adjusting the variables in the model is as follows:

$$
\widehat{\mathrm{LCI}}_{\mathrm{t}}=1.5309+0.8269 \mathrm{LEI}_{\mathrm{t}}+5.17 \mathrm{DI}_{\mathrm{t}}-6.67 \mathrm{DG}_{\mathrm{t}}(-1)
$$

These results comply with the practical situation. That is to say, the carbon intensity of the fifth category of provinces and regions is mainly influenced by energy intensity, industrial structure, and local fiscal expenditure. Carbon intensity is positively related to energy intensity and the proportion of the added value of the second industry, while it is negatively related to the proportion of the fiscal expenditure of the previous period. This means that the increase in the proportion of local fiscal expenditure in GDP is beneficial to decreasing carbon intensity.

\section{Discussion and Policy Proposals}

According the category listed and discussion conducted in section III, there are different factors influencing carbon intensity in different categories. Even though there may be the phenomena that different variables have different remarkable levels in different provinces for the same category, by integrating the laws, it is discovered that the carbon intensity of various provinces is mainly influenced by energy intensity, economic growth, the proportion of the second industry, and the fiscal expenditure. Basically, carbon intensity is positively related to energy intensity and economic growth. The correlation between carbon intensity and industrial structure, and that between carbon intensity and fiscal expenditure vary respectively. The carbon intensity of the second industry is positively related to energy intensity in some provinces (cities and autonomous regions), while it is negatively related in others, which is mainly due to the fact that the industrial structure of various provinces (cities and autonomous regions) is different, and that they have corresponding changing laws. The beneficial influence of fiscal expenditure on carbon intensity is insignificant, but the proportion of the fiscal expenditure is still positively related to carbon intensity. Moreover, theoretically, the forestation area, the investment on environmental pollution control, and the investment amount on state-owned energy industry shall be closely related to carbon intensity. However, due to the limited data, such variables have been deleted during model optimization as the coefficient symbol is inconsistent with the practical conditions. In the long run, the major way to realize energy saving and emission reduction of various provinces still lies in the adjustment of energy consumption structure, and the optimization and adjustment of industrial structure.

There are three major ways to reduce emission in various countries: firstly, optimization of energy consumption structure and the substitutive consumption with clean energy will greatly lower the emission of carbon dioxide in various regions and reduce environmental pollution without being at the cost of economic development. Secondly, the adjustment of economic development structure: the second industry, especially power generation industry, traffic transport industry and architectural industry, is the industry with more carbon emission. It is necessary to carry out an adjustment of economic structure unswervingly to realize the optimization and upgrading of industrial structure. Thirdly, establish market mechanism on energy saving and emission reduction with public expenditure, for example, carbon trading, carbon finance, and preferential and incentive policies on energy saving and emission reduction. According to the analysis in this study, the positive influence of government fiscal expenditure on carbon intensity is insignificant. This can mainly be because with the huge amount of fiscal expenditure only a small amount of expenditure is used on specific energy saving and emission reduction and also it is often impossible to accurately estimate the exact amount. In the long run, we do not agree to the way of realizing emission reduction merely through quantitative fiscal expenditure, because in our view low-carbon economy is to achieve a win-win situation between energy saving, emission reduction and economic development. Not only is achieving energy saving and emission reduction merely through fiscal expenditure totally ineffective, but sustainable development of low-carbon economy cannot be realized either. As a result, the following policy proposals have been put forth in this study:

1) From the perspective of industry, the development of industries involving of high-carbon technology shall be avoided. The government shall apply policy guidance and fiscal subsidy to guide the enterprises to carry out production with a high emission reduction technical cost. It shall also provide the industries an environment where they could apply "innovative technology", and thereby create a new commercial mode.

2) From the perspective of energy, the government shall formulate various policies and laws to encourage technological development of new energy, and carry out cooperation and exchanges with various countries 
frequently. And it shall strengthen development of energy technology, plan the long-term development of energy technology, and shall be good at using energy policy measures, and formulate policy and establish system from the perspective of environmental protection and sustainable development.

3) As for the environment, it is still necessary to establish a certification system in line with international practices, and to develop a domestic environmental management system in a sound way, to advocate green consumption concepts, and to promote environmental protection rules and system. To sustain the ecological environment, it is necessary to make a full investment on control and reconstruction of the ecological environment under the premise of giving sufficient consideration to the diversity of the ecological environment, for example, tree planting and forestation.

\section{References}

Ang, B. W., \& Pandiyan, G. (1997). Decomposition of energy-induced $\mathrm{CO}_{2}$ emissions in manufacturing. Energy Economics, 19(3), 363-374. http://dx.doi.org/10.1016/s0140-9883(96)01022-5

Ang, J. B. (2009). $\mathrm{CO}_{2}$ emissions, research and technology transfer in China. Ecological Economics, 68(10), 2658-2665. http://dx.doi.org/10.1016/j.ecolecon.2009.05.002

Annual Data of State Statistical Bureau of the PRC. (2007). Retrieved from http://www.stats.gov.cn/tjsj/ndsj/

Beijing Shuhuitong Environmental Technical Research Institute Co., Ltd. Retrieved from http://www.3edata.c

Bruntland, G. (1987). Our common future: The world commission on environment and development. The Top 50 Sustainability Books (pp. 52-55). Greenleaf Publishing in association with GSE Research. Retrieved from http://dx.doi.org/10.9774/gleaf.978-1-907643-44-6_12

Casler, S. D., \& Rose, A. (1998). Carbon dioxide emissions in the US economy: a structural decomposition $\begin{array}{lllll}\text { analysis. Environmental and resource economics, } & \text { 11(3-4), 349-363. }\end{array}$ http://dx.doi.org/10.1023/a:1008224101980

Department of Environmental Protection of the PRC. (2008). Retrieved from http://www.mep.gov.cn/

Fan, J., \& Zhou, Zh. M. (2000). Summary of Ecological Capital Research. Prediction, 19(005), 30-35. Retrieved from http://www.cqvip.com/Read/Read.aspx?id=4314048

Fang, J. Y., \& Chen, A. P. (2001). Dynamic Forest Biomass Carbon Pools in China and Their Significance. Botanic Journal, 43(9), 967-973. http://dx.doi.org/10.3321/j.issn:1672-9072.2001.09.014

Galinis, A., \& Van Leeuwen, M. J. (2000). A CGE model for Lithuania: The future of nuclear energy. Journal of Policy Modeling, 22(6), 691-718. http://dx.doi.org/10.1016/S0161-8938(98)00028-3

Gao, Tie-mei. (2009). Metric-economic Analytic Methods and Model Building-Eviews Application and Practical Examples (2ed.). (pp. 293,301,302). Beijing: Tsinghua University Press.

Gielen, D., \& Changhong, C. (2001). The $\mathrm{CO}_{2}$ emission reduction benefits of Chinese energy policies and environmental policies: A case study for Shanghai, period 1995-2020. Ecological Economics, 39(2), 257-270. http://dx.doi.org/10.1016/s0921-8009(01)00206-3

Holttinen, H., \& Tuhkanen, S. (2004). The effect of wind power on $\mathrm{CO}_{2}$ abatement in the Nordic Countries. Energy Policy, 32(14), 1639-1652. http://dx.doi.org/10.1016/s0301-4215(03)00158-7

Huang, L. (2008). Research on Development of Forestry Biomass Energy and Industrial Development in China. Beijing: Beijing Un $\quad$ Forestry Retrieved from http://cdmd.cnki.com.cn/Article/CDMD-10022-2009069446.htm

Kainuma, M., Matsuoka, Y., \& Morita, T. (2000). The AIM/end-use model and its application to forecast Japanese carbon dioxide emissions. European Journal of Operational Research, 122(2), 416-425. http://dx.doi.org/10.1016/s0377-2217(99)00243-x

Kaya, Y. (1990). Impact of carbon dioxide emission control on GNP growth: interpretation of proposed scenarios. IPCC Energy and Industry Subgroup, Response Strategies Working Group, Paris, 76. http://dx.doi.org/10.1016/0360-5442(90)90080-1

Lim, C. Y., Lee, B. W., \& Lee, K. J. (1998). Nuclear energy system for the global environmental regulation in Korea-Energy-economy interaction model analysis. Progress in Nuclear Energy, 32(3), 273-279. http://dx.doi.org/10.1016/S0149-1970(97)00072-3

Nakata, T. (2004). Energy-economic models and the environment. Progress in Energy and Combustion Science, 30(4), 417-475. http://dx.doi.org/10.1016/j.pecs.2004.03.001 
Pan, Sheng-chu. (2009). Intermediate Teaching Course on Metric-Economics (pp. 164). Beijing: Tsinghua University Press.

Proost, S., \& Van Regemorter, D. (1992). Economic effects of a carbon tax: with a general equilibrium illustration for Belgium. Energy economics, 14(2), 136-149. http://dx.doi.org/10.1016/0140-9883(92)90007-Z

Robinson, S., Yùnez-Naude, A., Hinojosa-Ojeda, R., Lewis, J. D., \& Devarajan, S. (1999). From stylized to applied models: Building multisector CGE models for policy analysis. The North American Journal of Economics and Finance, 10(1), 5-38. http://dx.doi.org/10.1016/S1062-9408(99)00014-5

Selden, T. M., Forrest, A. S., \& Lockhart, J. E. (1999). Analyzing the reductions in US air pollution emissions: 1970 to 1990. Land Economics, 1-21. http://dx.doi.org/10.2307/3146990

Shaw Daigee. (1993). Significances of Sustainable Development-Viewpoints in Economics. Taiwan Economic Forecast and Policy, 24(1), 43-61.

Shaw Daigee. (2010). Research on Prospect of Adaption to Climatic Changes in China, and Basis of Adaptation Policy Establishment[R], Commissioned by Environmental Protection Administration Executive Yuan, R.O.C. (Taiwan).

Sheinbaum, C., Ozawa, L., \& Castillo, D. (2010). Using logarithmic mean Divisia index to analyze changes in energy use and carbon dioxide emissions in Mexico's iron and steel industry. Energy Economics, 32(6), 1337-1344. http://dx.doi.org/10.1016/j.eneco.2010.02.011

Song, D. Y., \& Lu, Zh. B. (2009). The Factor Decomposition and Periodic Fluctuations of Carbon Emission in China. China Population Resources and Environment, 19(3), 18-24. http://dx.doi.org/10.3969\%2fj.issn.1002-2104.2009.03.005

Suri, V., \& Chapman, D. (1998). Economic growth, trade and energy: implications for the environmental Kuznets curve. Ecological Economics, 25(2), 195-208. http://dx.doi.org/10.1016/S0921-8009(97)00180-8

Unruh, G. C., \& Moomaw, W. R. (1998). An alternative analysis of apparent EKC-type transitions. Ecological Economics, 25(2), 221-229. http://dx.doi.org/10.1016/S0921-8009(97)00182-1

Wang, F., Wu, L. H., \& Yang, Ch. (2010). Driving Factors for Growth of Carbon Dioxide Emissions During Economic Development in China. Economic Research Journal, 2(123), 1.

WDI Statistical Index Database of World Bank. Retrieved from http://data.worldbank.org/data-catalog

Wu, L., Kaneko, S., \& Matsuoka, S. (2005). Driving forces behind the stagnancy of China's energy-related $\mathrm{CO}_{2}$ emissions from 1996 to 1999: the relative importance of structural change, intensity change and scale change. Energy Policy, 33(3), 319-335. http://dx.doi.org/10.1016/j.enpol.2003.08.003

Xu, G. Q., Liu, Z. Y., \& Jiang, Zh. H. (2006). Decomposition Model and Empirical Study of Carbon Emissions for China, 1995 - 2004. China Population Resources and Environment, 16(6), 158-161. http://dx.doi.org/10.3969\%2fj.issn.1002-2104.2006.06.030

Yin, X. G., \& Huo, T. (2010). A Synthesis of Foreign Scholars' Research on Low Carbon Economy. China Population, Resources and Environment, 20(9), 18-23. Retrieved from http://dx.chinadoi.cn/10.3969/j.issn.1002-2104.2010.09.004

Yu, G. Y. (2010). Research on Sustainable Development of Chinese Carbon-Sink Forestry and Competition Mechanism, Huazhong Agricultural University. Retrieved from http://cdmd.cnki.com.cn/Article/CDMD-10504-1011405576.htm

Yue, Ch., Hu, X. Y., He, H. F., Zhu, J. L., Wang, Sh. P., \& Fang, J. Y. (2010). Provincial Carbon Emissions and Carbon Intensity in China from 1995 to 2007 (Carbon Emissions and Social Development, III). Acta Scientiarum Naturalium Universitatis Pekinensis, 46(4), 510-516. http://ir.calis.edu.cn/hdl/211010/2328

\section{Notes}

Note 1.There is no relevant statistical data in Tibetan areas. 


\section{Appendix A}

Table A1. The references of regression variables

\begin{tabular}{|c|c|c|c|}
\hline Variable & Meaning & Index Calculation & Reference \\
\hline LCI & Carbon Intensity & $\begin{array}{l}\mathrm{Ln} \text { ( carbon emission of various } \\
\text { provinces/GDP of various provinces) }\end{array}$ & $\begin{array}{l}\text { Yoichi } \\
\text { Kaya(1990); YUE } \\
\text { Chao (2010) }\end{array}$ \\
\hline LEI & Energy Intensity & $\begin{array}{l}\text { Ln(Energy Consumption of Each Province/ } \\
\text { GDP of various provinces) }\end{array}$ & $\begin{array}{l}\text { Yoichi } \\
\text { Kaya(1990),Libo } \\
\text { WU et al. }(2005) \\
\text { WANG Feng(2010) }\end{array}$ \\
\hline DI & Industrial Structure & $\begin{array}{l}\text { Added Value of Second Industry of Each } \\
\text { Province/ GDP of various provinces) }\end{array}$ & $\begin{array}{l}\text { B.W. Ang\& G. } \\
\text { Pandiyan (1997) }\end{array}$ \\
\hline g_GDP & Economic Growth & Growth rate of regional GDP & $\begin{array}{l}\text { Yoichi Kaya(1990), } \\
\text { Claudia S. et al. } \\
(2010)\end{array}$ \\
\hline DG & Fiscal expenditure & $\begin{array}{l}\text { Total amount of local fiscal } \\
\text { expenditure/regional GDP }\end{array}$ & Selected by research \\
\hline EI_nat & $\begin{array}{l}\text { State-owned energy } \\
\text { industrial investment }\end{array}$ & $\begin{array}{l}\text { Investment on state-owned energy industry } \\
\text { in each province/regional GDP }\end{array}$ & Selected by research \\
\hline EPI & $\begin{array}{l}\text { Investment on } \\
\text { environmental } \\
\text { pollution control }\end{array}$ & $\begin{array}{l}\text { Investment on environmental pollution } \\
\text { control of each province/regional GDP }\end{array}$ & Selected by research \\
\hline Fore & Total forestation area & $\begin{array}{l}\text { Total forestation area of each } \\
\text { province/national total area of forestation }\end{array}$ & Selected by research \\
\hline
\end{tabular}

\section{Copyrights}

Copyright for this article is retained by the author(s), with first publication rights granted to the journal.

This is an open-access article distributed under the terms and conditions of the Creative Commons Attribution license (http://creativecommons.org/licenses/by/3.0/). 